\title{
Effects of 6-month vitamin D supplementation on insulin sensitivity and secretion: a randomised, placebo-controlled trial
}

\author{
Patricia Lemieux', S John Weisnagel ${ }^{1,2}$, Annabelle Z Caron ${ }^{1}$, Anne-Sophie Julien ${ }^{3}$, Anne-Sophie Morisset ${ }^{2,4,5}$, \\ Anne-Marie Carreau' , Jonathan Poirier', André Tchernof 2,4,5,6, Julie Robitaille, ${ }^{2,4,5}$, Jean Bergeron ${ }^{1,2}$, \\ André Marette ${ }^{1,2,5,6}$, Marie-Claude Vohl4,5 and Claudia Gagnon ${ }^{1,2,5}$
}

'Department of Medicine, Université Laval, Québec City, Québec, Canada, ²Endocrinology and Nephrology Unit, CHU de Québec-Université Laval Research Centre, Québec City, Québec, Canada, ${ }^{3}$ Department of Mathematics and Statistics, Québec City, Québec, Canada, ${ }^{4}$ School of Nutrition, Laval University, Québec City, Québec, Canada, ${ }^{5}$ Institute of Nutrition and Functional Foods, Québec City, Québec, Canada, and ${ }^{6}$ Quebec Heart and Lung Institute Research Centre, Québec City, Québec, Canada

\section{Correspondence} should be addressed to C Gagnon Email

claudia.gagnon@ crchudequebec.ulaval.ca

\begin{abstract}
Objective: To determine whether vitamin $\mathrm{D}_{3}$ supplementation improves insulin sensitivity, using the hyperinsulinemiceuglycemic clamp.

Design: This single-centre, double-blind, placebo-controlled trial randomised 96 participants at high risk of diabetes or with newly diagnosed type 2 diabetes to vitamin $D_{3} 5000 \mathrm{IU}$ daily or placebo for 6 months.

Methods: We assessed at baseline and 6 months: (1) primary aim: peripheral insulin sensitivity (M-value using a 2-h hyperinsulinemic-euglycemic clamp); (2) secondary aims: other insulin sensitivity (HOMA2\%S, Matsuda) and insulin secretion (insulinogenic index, C-peptide area under the curve, HOMA2-B) indices using a 2-h oral glucose tolerance test (OGTT); $\beta$-cell function (disposition index: M-value $\times$ insulinogenic index); fasting and 2 -h glucose post OGTT; $\mathrm{HbA}_{1 \mathrm{c}}$; anthropometry.

Results: Baseline characteristics were similar between groups (\% or mean \pm s.D.): women $38.5 \%$; age $58.7 \pm 9.4$ years; BMI $32.2 \pm 4.1 \mathrm{~kg} / \mathrm{m}^{2}$; prediabetes $35.8 \%$; diabetes $20.0 \%$; 25-hydroxyvitamin $\mathrm{D}(25(\mathrm{OH}) \mathrm{D}) 51.1 \pm 14.2 \mathrm{nmol} / \mathrm{L}$. At 6 months, mean $25(\mathrm{OH}) \mathrm{D}$ reached $127.6 \pm 26.3 \mathrm{nmol} / \mathrm{L}$ and $51.8 \pm 16.5 \mathrm{nmol} / \mathrm{L}$ in the treatment and placebo groups, respectively $(P<0.001)$. A beneficial effect of vitamin $\mathrm{D}_{3}$ compared with placebo was observed on $\mathrm{M}$-value (mean change ( $95 \% \mathrm{Cl}): 0.92(0.24-1.59)$ vs $-0.03(-0.73$ to 0.67$) ; P=0.009)$ and disposition index (mean change $(95 \% \mathrm{Cl})$ : $267.0(-343.4$ to 877.4 ) vs $-55.5(-696.3$ to 585.3$) ; P=0.039$ ) after 6 months. No effect was seen on other outcomes. Conclusions: In individuals at high risk of diabetes or with newly diagnosed type 2 diabetes, vitamin $D$ supplementation for 6 months significantly increased peripheral insulin sensitivity and $\beta$-cell function, suggesting that it may slow metabolic deterioration in this population.
\end{abstract}

\section{Introduction}

Low serum 25-hydroxyvitamin D (25(OH)D) has been associated with an increased risk of developing insulin resistance and type 2 diabetes in prospective observational studies $(1,2)$. Since low vitamin D status is highly prevalent worldwide (3), the potential role of vitamin D supplementation in improving glucose homeostasis generated great enthusiasm among scientists and clinicians. However, randomised controlled trials (RCTs) https://eje.bioscientifica.com https://doi.org/10.1530/EJE-19-0156 (c) 2019 European Society of Endocrinology Printed in Great Britain
Published by Bioscientifica Ltd. 
of vitamin D supplementation have shown inconstant effects on measures of insulin sensitivity, insulin secretion and $\beta$-cell function. A meta-analysis concluded that variable results among RCTs could be explained by heterogeneous study populations in terms of ethnicity, glucose tolerance and vitamin D status, by variations in vitamin $\mathrm{D}$ dosage and duration of treatment and by use of surrogate measures of insulin sensitivity $(4,5)$. Yet, the five studies that used the gold-standard method to assess insulin sensitivity, the hyperinsulinemic-euglycemic clamp, found no effect of vitamin D supplementation on insulin sensitivity $(6,7,8,9,10)$. However, three of these trials were limited by small sample size $(n=12-18)(6,7$, $8)$. Despite adequate sample size $(n=62-65)$ and robust methodology, the two other studies failed to show benefits of vitamin $\mathrm{D}$ in metabolically healthy overweight or obese subjects (10) and in individuals with long-standing type 2 diabetes (9).

The primary aim of this 6-month trial was to determine whether vitamin $\mathrm{D}_{3}$ supplementation improves peripheral insulin sensitivity (M-value) in individuals at high risk for type 2 diabetes or with newly diagnosed type 2 diabetes, using the gold-standard hyperinsulinemic-euglycemic clamp. Secondary aims were to evaluate the effects of vitamin $\mathrm{D}_{3}$ on: fasting- and OGTT-derived indices of insulin sensitivity, insulin secretion, $\beta$-cell function, metabolic markers, blood pressure and anthropometric measurements.

\section{Methods}

\section{Study design}

This randomised, double-blind, placebo-controlled, parallel-group trial was conducted at a single site (Centre Hospitalier Universitaire (CHU) de Québec-Université Laval) located in Québec City, Canada. After screening, eligible participants were randomly assigned, in a 1:1 ratio, to receive vitamin $\mathrm{D}_{3}$ or placebo for 6 months. Randomisation, computerised based on the Pocock and Simon minimisation method (11), was conducted by a biostatistician to balance treatment arms according to sex, BMI ( $<$ or $\geq 30 \mathrm{~kg} / \mathrm{m}^{2}$ ) and age $(<$ or $\geq 50$ years old). The biostatistician sent treatment allocation directly to the pharmacist who was in charge of dispensing the study medication. The investigators, research personnel, care providers and participants involved in this study were blinded to the treatment assignment until the last participant completed the study.
The study protocol and all amendments were approved by the CHU de Québec-Université Laval Ethics Committee. The study was registered at clinicaltrials.gov before starting recruitment (NCT01779908) and conduct of the trial followed the 2010 Consort guidelines (12). This study was also conducted according to the guidelines laid down in the Declaration of Helsinki and all procedures involving patients were approved by the CHU de QuébecUniversité Laval Ethics Committee (Project number B12-12-1095). Written informed consent was obtained from each participant before any trial-related activities.

\section{Participants}

Participants were recruited between January 2013 and October 2016 via flyers in hospitals and public places, through newspapers and radio advertisements and via emails sent to employees of the CHU de Québec-Université Laval and Université Laval. Initially, eligible participants included vitamin D-deficient $(25(\mathrm{OH}) \mathrm{D} \leq 50 \mathrm{nmol} / \mathrm{L})$ Caucasian men and postmenopausal women aged $\geq 50$ years, meeting the criteria of the hypertriglyceridemic waist phenotype (waist circumference $\geq 90 \mathrm{~cm}$ plus fasting triglycerides $\geq 2.0 \mathrm{mM}$ in men or waist circumference $\geq 85 \mathrm{~cm}$ plus fasting triglycerides $\geq 1.5 \mathrm{mM}$ in women). During the trial, inclusion criteria were modified a few times to improve the recruitment rate. Eligible participants finally included Caucasian men and women aged $\geq 25$ years with a serum $25(\mathrm{OH}) \mathrm{D}$ at screening $\leq 55 \mathrm{nmol} / \mathrm{L}$, an increased waist circumference $(\geq 102 \mathrm{~cm}$ for men and $\geq 88 \mathrm{~cm}$ for women) and at least one metabolic abnormality or risk factor associated with insulin resistance. Those were defined as (1) fasting triglycerides $\geq 1.7 \mathrm{mM}$ or dyslipidemia treated with lipidlowering drugs, (2) prediabetes or type 2 diabetes not on glucose-lowering drugs: fasting glucose $\geq 5.6 \mathrm{mM}$ or 2 -h glucose post OGTT $\geq 7.8 \mathrm{mM}$ or $\mathrm{HbA}_{1 \mathrm{c}} \geq 5.7 \%$, (3) firstdegree relative with type 2 diabetes and (4) history of gestational diabetes.

Participants were excluded if they had any of the following conditions: type 2 diabetes under drug therapy, $\mathrm{HbA}_{1 \mathrm{c}}>7 \%$, BMI $\geq 40 \mathrm{~kg} / \mathrm{m}^{2}$, medication influencing vitamin D or glucose metabolism in the last 3 months, regular consumption of supplements containing $>400$ IU/day of vitamin $\mathrm{D}_{3}$ over the last 2 months, renal insufficiency (estimated glomerular filtration rate $<60 \mathrm{~mL} / \mathrm{min}$ ), pregnancy, cirrhosis, intestinal malabsorption (e.g. bypass surgery, celiac disease) or osteoporosis, history of nephrolithiasis, hypercalcaemia $(>2.6 \mathrm{mM})$, hypercalciuria $\quad(>0.6$ fasting urine 
calcium/creatinine ratio), $>5 \%$ change in weight in the last 3 months, diseases affecting glucose metabolism (e.g. hyperthyroidism), pacemaker (for bioimpedance only); inability to provide informed consent and complete questionnaires due to physical or mental problems.

\section{Intervention}

The treatment group received $5,000 \mathrm{IU}$ of vitamin $\mathrm{D}_{3}$ once a day (half a tablet of D-tabs 10,000IU, Riva Laboratory, Québec, Canada), aimed to reach serum 25(OH)D $\geq 75 \mathrm{nmol} / \mathrm{L}$ (13), whereas the control group received placebo daily, for 6 months. Placebo pills were produced by the hospital pharmacy using lactose monohydrate powder. To ensure blinding, both the vitamin D and placebo pills were enrobed in capsules of identical shape and colour. The pharmacy department dispensed study pills and asked participants to take the pill with the morning meal. The pharmacist assessed compliance with treatment at 3 and 6 months using pill count. Participants were questioned about adverse effects or change in their health condition during the intervention. All participants were instructed to maintain their usual diet and exercise habits throughout the study. Medication was assessed at baseline and any further change was documented during follow-up. An independent blinded clinician performed safety monitoring of serum calcium at 3 months.

\section{Outcome measures}

\section{Hyperinsulinemic-euglycemic clamp}

The primary endpoint was change between baseline and 6 months in peripheral insulin sensitivity, measured by M-value, using a 2-h hyperinsulinemic-euglycemic clamp. Participants were instructed to eat the same dinner the night before the clamp at 0 and 6 months and to avoid physical activity (except walking), alcohol and caffeine for $24 \mathrm{~h}$ prior to the procedure. After a 12-h overnight fast, an intravenous catheter was placed in an antecubital vein for the administration of regular insulin (Humulin ${ }^{\circledR}$ R) and dextrose $20 \%$. A second catheter was placed in the other arm for blood sampling. Insulin was infused at a fixed rate of $40 \mathrm{mU} / \mathrm{m}^{2} / \mathrm{min}$. Dextrose infusion rate was adjusted every $5 \mathrm{~min}$ to maintain capillary glucose measurement (using Xceed Pro and Accu-Chek Inform II glucose metres) between 5.0 and $5.5 \mathrm{mM}$. Serum insulin was measured every $5 \mathrm{~min}$ during the last $30 \mathrm{~min}$ of the clamp. M-value, an index of stimulated glucose disposal rate, was obtained by dividing exogenous glucose infusion rate by kilogram of body weight during the last 30 minutes $(\mathrm{mg} / \mathrm{kg} \times \mathrm{min})$. Another index of peripheral insulin sensitivity $(\mathrm{M} / \mathrm{I})$, defined as M-value divided by the mean serum insulin concentration during the last 30 min of the clamp, was calculated.

\section{Oral glucose tolerance test}

After a 12-h fast, a $75 \mathrm{~g}$ 2-h OGTT was performed in the morning at baseline and at 6 months. The OGTT was scheduled in a period of 1 to 7 days prior to or after the hyperinsulinemic-euglycemic clamp. Blood samples were collected through a venous catheter in serum separating tubes (SST) at 0, 15, 30, 60, 90 and $120 \mathrm{~min}$ for measurement of insulin, glucose and C-peptide concentrations. Hepatic insulin sensitivity was assessed by HOMA2\%S using fasting glucose and insulin concentrations (HOMA2 calculator - www.dtu.ox.ac.uk/ homa) and whole-body insulin sensitivity was assessed by Matsuda index (10,000 divided by the squared root of ((fasting glucose $\times$ fasting insulin $) \times\left(\right.$ mean glucose $\mathrm{e}^{30-120}$ ${ }^{\min } \times$ mean insulin $\left.{ }^{30-120 \mathrm{~min}}\right)$ ). Matsuda index was added a posteriori for comparison with previously published studies. Insulin secretion was assessed by HOMA2-B using fasting C-peptide and glucose (HOMA2 calculator), the insulinogenic index (delta C-peptide ${ }^{0-30}$ min divided by delta glucose $\mathrm{e}^{0-30 \mathrm{~min}}$ ) and the area under the curve (AUC) for C-peptide. Disposition index, calculated by multiplying M-value by insulinogenic index, was used to estimate $\beta$-cell function.

\section{Anthropometry and blood pressure}

Blood pressure and anthropometric measurements including weight, height, waist and hip circumference were assessed at baseline and every 3 months. Participants were weighed without shoes in light clothing on a calibrated scale to the nearest $0.1 \mathrm{~kg}$. Height was measured at the nearest millimetre, using a wall-mounted stadiometer. BMI was calculated in $\mathrm{kg} / \mathrm{m}^{2}$. Blood pressure was measured three times in a sitting position after a 15-min rest; the mean of the last two measurements was calculated. Waist circumference was measured twice, at the nearest $0.5 \mathrm{~cm}$, using a tape placed on top of the upper iliac crest, at the end of a normal expiration. Hip circumference was measured in duplicate, at the nearest millimetre, using a tape placed at the maximum width of the buttocks. Percent body fat was calculated by bioimpedance, using the InBody520 device. 


\section{Serum 25(OH)D, parathyroid hormone and metabolic markers}

Serum was stored at $-80^{\circ} \mathrm{C}$ until the end of the study, where samples were analysed in a single batch for all biomarkers. For screening of the participants, serum 25(OH)D was analysed by an electrochemiluminescence immunoassay (Roche, Cobas 6000, CV 10\%), which was more readily available. However, for all statistical analyses, serum 25(OH)D was analysed in a single batch at the study end for assessment of baseline, 3-month and 6-month frozen samples by ultra-performance liquid-chromatography tandem mass spectrometry (Waters ACQUITY UPLC System, CV 7.3\%). The department of biochemistry measuring serum 25(OH)D met the performance target set by the DEQAS Advisory Panel. PTH was assessed by a chemiluminescence immunoassay (Beckman Coulter, Access 2, CV 4\%), while $\mathrm{HbA}_{1 \mathrm{c}}$ was measured by a secondgeneration colorimetric method (Roche, Integra 800, CV 4\%). Plasma glucose was measured enzymatically by the hexokinase method (Roche, Modular E170, CV $1.8 \%)$, whereas insulin and C-peptide were measured with an electrochemiluminescence immunoassay (Roche, Modular E170, CV 3 and 2.5\%, respectively). Calcium was measured via the o-cresolphthalein complexone method (Roche, Modular E170, CV 3.6\%) every 3 months for safety purposes.

\section{Diet, physical activity and sun exposure}

Weekly sun exposure was calculated (h/week) via a non-validated questionnaire, based on the time that participants reported spending outdoors between 11:00 $\mathrm{h}$ and 14:00h over the last 3 months (14), excluding days between November 1st and March 31th, as there is no skin production of vitamin $\mathrm{D}_{3}$ during that period in Québec City. Participants were also asked about their sunscreen use (sun protection factor, frequency), clothes worn (hat, shirt, pants, long sleeves, etc.) and localisation (shadow, sun) while performing outdoor activities. Physical activity habits during the last week before the baseline and 6-month study visits were estimated using the short International Physical Activity Questionnaire (IPAQ, 2005). The volume of activity per week (walking, moderate and vigorous physical activity) was computed by weighting each type of activity by its energy requirements (METs) and by multiplying by the number of corresponding days per week. Results were summed to yield a score in MET-minutes per week. Finally, a Web-based, food frequency questionnaire, validated in the Québec City metropolitan area, was administered to evaluate daily energy, vitamin $\mathrm{D}$ and calcium intakes both at the beginning and at the end of the study (15).

\section{Statistical methods}

As there was no available similar study to estimate the mean M-value of our study population when the study was planned, our sample size was based on the mean M-value $(5.49 \pm 2.33)$ of 65 vitamin D-deficient postmenopausal women aged 50-68 years with a waist circumference measurement of $>88 \mathrm{~cm}$ who had taken part in a cross-sectional study conducted in the Québec City area (unpublished result). We hypothesised that the M-value would remain stable between baseline and 6 months in the control group, while it would increase by $22 \%$ in the treatment group. This was based on the study by von Hurst et al., who showed that vitamin D-deficient South Asian women with insulin resistance who reached serum $25(\mathrm{OH}) \mathrm{D}$ concentrations $>80 \mathrm{nmol} / \mathrm{L}$ with vitamin D supplementation experienced an increase in insulin sensitivity (HOMA-IS) by $22 \%$ versus placebo at 6 months (16). This difference corresponds to a medium effect with a Cohen's d of 0.52 (17). The trial was designed to recruit a total of 120 participants, providing a statistical power of $80 \%$ to detect this clinically significant difference between groups at 6 months with a Student's t-test and with an alpha error of 0.05 . To account for a dropout rate of $10 \%$, sample size was increased at 130 participants.

Statistical analyses were performed by an independent statistician using SAS version 9.4 (SAS Institute Inc.). Group comparability at baseline was assessed using Student's $t$-test and chi-squared tests for continuous and categorical variables, respectively. Baseline comparison between participants who completed the study and those who dropped out was performed using the same tests. Changes from baseline to endpoint measures of primary and secondary outcomes between and within groups were assessed using repeated-measures two-way analyses of variance (rmANOVA). Treatment and time effects and their interaction on outcome measures were tested. The interaction term (time-by-treatment effect) is the term of interest as it tests whether the temporal change differs between groups. The treatment term tests if a difference exists between groups, for all visits combined, while the time term tests if a difference exists between visits, for all groups. rmANOVA were estimated using a linear mixed model. These models were adjusted for variables that differed at baseline between groups. Squared-root transformation was used when needed to meet model 
assumptions, such as normality and homoscedasticity of the residuals. According to the intention-to-treat principle, data were analysed for all randomised participants regardless of compliance to treatment and dropout. Linear mixed model enables to use all the available data, even if no values are present after baseline for an individual; thus, no participant was excluded from the analysis. A sensitivity analysis was also conducted for the primary outcome (M-value by clamp), excluding participants with hypoglycaemia (capillary blood glucose $<4.0 \mathrm{mmol} / \mathrm{L}$ ) at any timepoint during the clamp and/or with a difference of $\geq 0.5 \mathrm{mmol} / \mathrm{L}$ between mean capillary blood glucose in the last $30 \mathrm{~min}$ of the clamp at 0 and 6 months. A prespecified subgroup analysis was performed per-protocol, including participants who took $\geq 80 \%$ of their study medication. Moreover, post hoc exploratory subgroup analyses were done according to baseline glucose tolerance status (normal glucose tolerance versus prediabetes versus diabetes) and baseline $25(\mathrm{OH}) \mathrm{D}(<50 \mathrm{nmol} / \mathrm{L})$.

\section{Results}

Due to difficulties enrolling participants in the trial, recruitment was stopped after randomising the 96th participant. Out of the 796 screened participants, 96 met the inclusion criteria and were randomised, 48 in each group (Fig. 1). Main reasons for exclusion were absence of serum 25(OH)D criterion $(n=185)$, declined participation $(n=154)$, waist circumference below defined inclusion criteria $(n=104)$, consumption of vitamin D supplements $(n=65)$ or diabetes medication $(n=42)$ and absence of risk factors associated with insulin resistance $(n=38)$. One participant in the treatment group withdrew after the first part of the baseline study visit (did not undergo the OGTT nor the clamp) for personal reasons and did not receive the allocated intervention. Four participants in the placebo group withdrew during the trial and did not complete the follow-up visits. Reasons for withdrawal were personal reasons $(n=2)$ or experiencing side effects $(n=2)$.

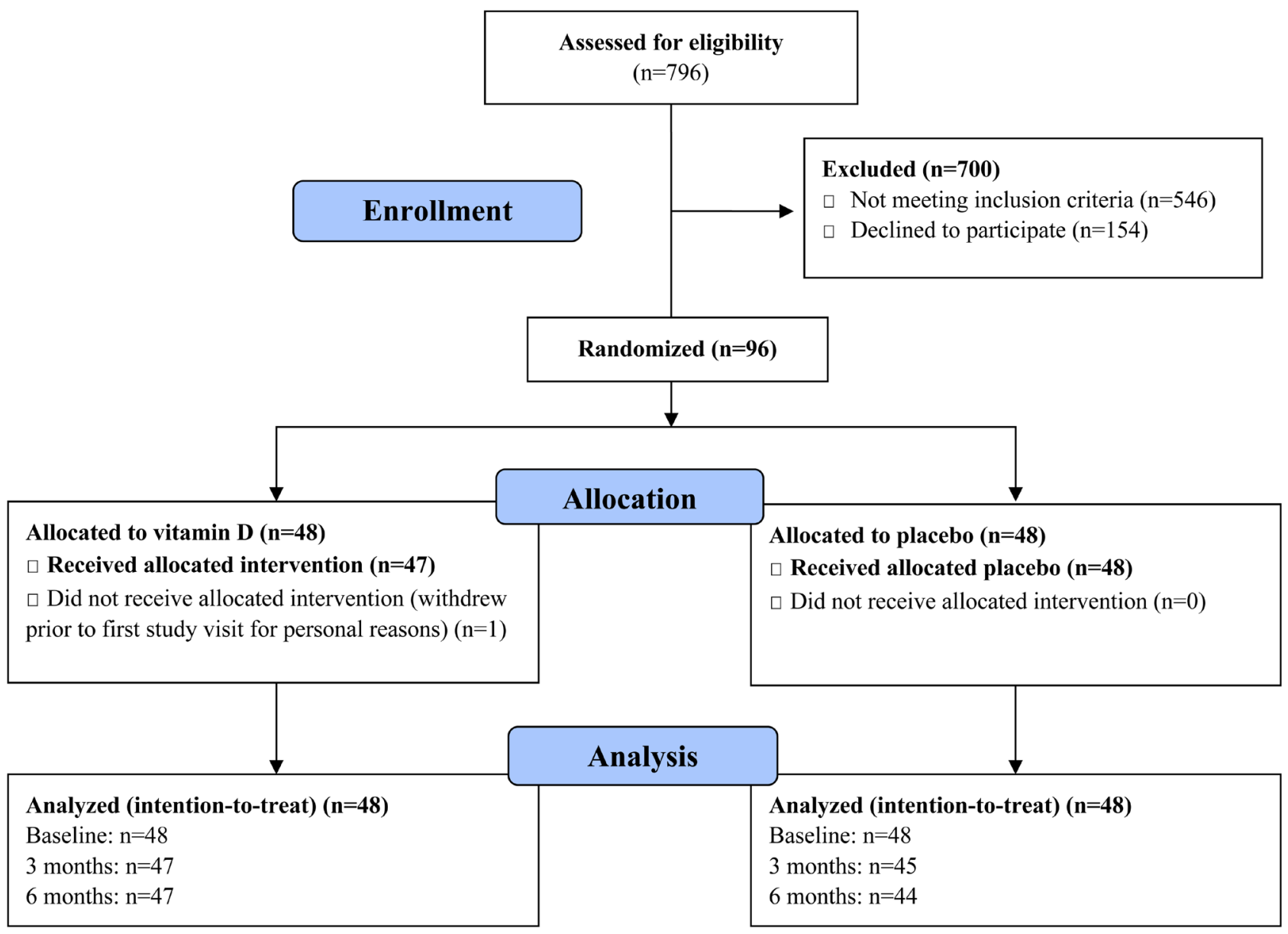

Figure 1

Flowchart showing participant enrolment, allocation and analysis. 
Moreover, three more participants stopped taking the study supplementation during the trial because of adverse effects (treatment $n=2$, placebo $n=1$ ) but completed the follow-up visits. Finally, one participant in the placebo group had no data for the primary outcome due to impossibility to insert an intravenous catheter to perform the hyperinsulinemic-euglycemic clamp. Compared to the participants who did not complete the study, those who completed had a worse insulin sensitivity profile, as determined by significantly lower HOMA2\%S (40.6 vs $62.4, P=0.008$ ) and Matsuda (2.14 vs $3.51, P=0.015$ ) indices. There was also a trend for the inclusion of more men (63.7 vs $20.0 \%, P=0.071)$ with higher fasting glucose $(6.0$ vs $5.2 \mathrm{mmol} / \mathrm{L}, P=0.079)$ and insulin (130 vs $81 \mathrm{pmol} / \mathrm{L}, P=0.091)$ concentrations.

Baseline characteristics of the 96 randomised participants are shown in Table 1. Participants were a majority of men in their 50s with obesity. Over half of the participants had either prediabetes $(35.8 \%)$ or newly diagnosed type 2 diabetes (20\%). Mean baseline serum $25(\mathrm{OH}) \mathrm{D}$ concentration by mass spectrometry was $51.1 \mathrm{nmol} / \mathrm{L}$, with $45.8 \%$ of the participants having a $25(\mathrm{OH}) \mathrm{D}$ concentration $\leq 50 \mathrm{nmol} / \mathrm{L}$ (min-max: treatment, $\quad 19-81 \mathrm{nmol} / \mathrm{L} ; \quad$ placebo, $25-97 \mathrm{nmol} / \mathrm{L})$. Baseline characteristics were similar for both groups, except for significantly lower serum triglycerides in the treatment group, a trend for a higher dietary vitamin $\mathrm{D}$ intake and for a lower serum 25(OH)D concentration in the treatment group. Difference in 25(OH)D between groups was thought to be potentially clinically significant and therefore, results were adjusted for baseline $25(\mathrm{OH})$ D. As further adjustment for serum triglycerides did not change results, these data are not presented.

\section{Change in serum 25(OH)D concentrations and compliance with study medication}

Serum 25(OH)D was significantly higher in the treatment group at 3 months $(122.9$ vs $52.2 \mathrm{nmol} / \mathrm{L}, P<0.001)$ and 6 months (127.6 vs $51.8 \mathrm{nmol} / \mathrm{L}, P<0.001)$ compared with the control group. After 6 months, serum 25(OH) D increased by a mean of $79.1 \mathrm{nmol} / \mathrm{L}$ (95\% CI 73.1, 85.2) in the treatment group and did not change in the placebo group $(1.87 \mathrm{nmol} / \mathrm{L}(95 \% \mathrm{CI}-4.33,8.07))$ (Fig. 2). Moreover, $95.7 \%$ of the participants in the treatment group reached a serum $25(\mathrm{OH}) \mathrm{D}$ value of $>75 \mathrm{nmol} / \mathrm{L}$ at 6 months. Compliance was similar in both groups, with 93.2 and $88.6 \%$ of the participants in the treatment and control groups who took $\geq 80 \%$ of their study medication, respectively $(P=0.713)$. Compliance data were missing for eight participants.

\section{Change in primary outcome (M-value)}

At baseline, $80.9 \%(n=38 / 47)$ of participants in both groups reached the target capillary blood glucose during the last $30 \mathrm{~min}$ of the clamp while at 6 months, $85.1 \%$ $(n=40 / 47)$ and $83.7 \% \quad(n=36 / 43)$ of participants in treatment and placebo groups, respectively met this criterion. There was a significant time-by-treatment interaction for insulin sensitivity, as assessed by M-value and $\mathrm{M} / \mathrm{I}$ ratio, in favour of the vitamin $\mathrm{D}$ group (Table 2 ). Indeed, M-value increased by a mean of $22.9 \%$ in the treatment group, while it remained stable in the placebo group. Results were similar in the sensitivity analysis including participants who had no hypoglycaemia and/or a difference $<0.5 \mathrm{mmol} / \mathrm{L}$ between mean capillary blood glucose in the last $30 \mathrm{~min}$ of the clamp at 0 and 6 months $(n=72)$. A post hoc exploratory subgroup analysis revealed that between-group differences in M-value appeared to be more important in participants with diabetes or prediabetes at baseline (Table 3). A second post hoc subgroup analysis restricted to participants with baseline serum 25(OH)D $<50 \mathrm{nmol} / \mathrm{L}(n=44)$ no longer demonstrated a significant between-group difference for change in M-value.

\section{Changes in secondary outcomes (insulin sensitivity, insulin secretion, $\beta$-cell function, metabolic markers, blood pressure and anthropometric measures)}

No between-group differences were observed for changes in insulin sensitivity and insulin secretion indices derived from fasting values or the OGTT (Table 4). However, there was a significant time-by-treatment interaction $(P=0.039)$ for disposition index, calculated as M-valuexinsulinogenic index, with stability in the control group and improvement in the treatment group at 6 months. Changes in fasting glucose, 2-h glucose post OGTT and $\mathrm{HbA}_{1 \mathrm{c}}$ were similar between groups. Moreover, changes in weight, BMI, waist and hip circumference, body fat mass and blood pressure did not differ between the intervention and placebo groups (Table 5). Subgroup analyses restricted to participants who took $\geq 80 \%$ of their study medication or to those with abnormal baseline glucose tolerance status (prediabetes or diabetes) gave similar results. 
Table 1 Baseline characteristics of the participants by treatment groupa.

\begin{tabular}{|c|c|c|c|}
\hline & Treatment, $n=48$ & Placebo, $n=48$ & $P$ value $^{\mathrm{b}}$ \\
\hline Age, years & $58.3(8.8)$ & $59.1(9.5)$ & 0.674 \\
\hline Women & 41.7 & 35.4 & 0.675 \\
\hline Menopausal women & 85.0 & 82.4 & 1.000 \\
\hline Season of recruitment & & & 0.782 \\
\hline Winter & 29.2 & 29.2 & \\
\hline Spring & 35.4 & 29.2 & \\
\hline Summer & 16.7 & 25.0 & \\
\hline Fall & 18.8 & 16.7 & \\
\hline Education & & & 0.127 \\
\hline Primary school & 0.0 & 4.2 & \\
\hline High school & 16.7 & 22.9 & \\
\hline College & 14.6 & 25.0 & \\
\hline University & 68.8 & 47.9 & \\
\hline Family income & & & 0.489 \\
\hline $0-19,000 \$$ & 10.4 & 2.1 & \\
\hline $20,000-39,000 \$$ & 10.4 & 14.6 & \\
\hline $40,000-59,000 \$$ & 16.7 & 22.9 & \\
\hline $60,000-79,000 \$$ & 14.6 & 16.7 & \\
\hline $80,000-99,000 \$$ & 14.6 & 16.7 & \\
\hline$>100,000 \$$ & 29.2 & 27.1 & \\
\hline Declined to answer & 4.2 & 0.0 & \\
\hline Current smoking & 8.3 & 4.2 & 0.677 \\
\hline First-degree relative with diabetes & 59.6 & 47.9 & 0.306 \\
\hline $\mathrm{BMI}, \mathrm{kg} / \mathrm{m}^{2}$ & $32.2(4.3)$ & $32.1(3.9)$ & 0.889 \\
\hline Waist circumference, cm & $107.9(9.0)$ & $108.5(9.5)$ & 0.760 \\
\hline Systolic blood pressure, mmHg & $129.2(13.6)$ & $131.2(17.3)$ & 0.532 \\
\hline Diastolic blood pressure, $\mathrm{mmHg}$ & $76.2(9.3)$ & $76.5(9.7)$ & 0.862 \\
\hline $\mathrm{HbA}_{1 \mathrm{c}} \%$ & $5.7(0.3)$ & $5.8(0.3)$ & 0.678 \\
\hline Fasting glucose, $\mathrm{mmol} / \mathrm{L}$ & $5.9(0.8)$ & $6.1(1.1)$ & 0.588 \\
\hline Fasting insulin, pmol/L & $130.7(60.0)$ & $125.4(54.0)$ & 0.649 \\
\hline 2-h glucose post OGTT, $\mathrm{mmol} / \mathrm{L}$ & $8.2(3.4)$ & $8.4(3.1)$ & 0.745 \\
\hline Glucose status & & & 0.895 \\
\hline Prediabetes $^{c}$ & 34.0 & 37.5 & \\
\hline Diabetes $^{d}$ & 19.1 & 20.8 & \\
\hline 25-Hydroxyvitamin $\mathrm{D}^{\mathrm{e}}, \mathrm{nmol} / \mathrm{L}$ & $48.5(13.0)$ & $53.7(15.0)$ & 0.073 \\
\hline Parathyroid hormone, ng/L & $57.3(21.2)$ & $57.3(20.3)$ & 0.992 \\
\hline Corrected calcium, $\mathrm{mmol} / \mathrm{L}$ & $2.25(0.08)$ & $2.27(0.07)$ & 0.251 \\
\hline Serum creatinine, $\mu \mathrm{mol} / \mathrm{L}$ & $74.6(14.1)$ & $73.9(13.1)$ & 0.800 \\
\hline Triglycerides, $\mathrm{mmol} / \mathrm{L}$ & $1.66(0.65)$ & $2.33(1.90)$ & 0.023 \\
\hline $\mathrm{ALT}, \mathrm{U} / \mathrm{L}$ & $26.5(14.0)$ & $29.6(14.5)$ & 0.302 \\
\hline Urinary calcium/creatinine ratio, mmol/mmolcr & $0.19(0.15)$ & $0.17(0.11)$ & 0.623 \\
\hline Time spent outdoor between $11 \mathrm{~h}$ and $14 \mathrm{~h}$, h/week & $4.0(4.9)$ & $3.6(4.8)$ & 0.738 \\
\hline Physical activity, MET, min/week & 1709 (1928) & $1371(1798)$ & 0.377 \\
\hline Percent body fat ${ }^{f} \%$ & $38.5(8.3)$ & $37.4(7.8)$ & 0.581 \\
\hline Daily energy intake, kJ & $11740(3879)$ & $11033(3075)$ & 0.328 \\
\hline Dietary vitamin D intake, IU/day & $380(228)$ & $312(168)$ & 0.086 \\
\hline Dietary calcium intake, mg/day & $1528(678)$ & $1352(512)$ & 0.153 \\
\hline
\end{tabular}

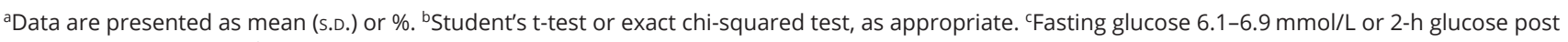

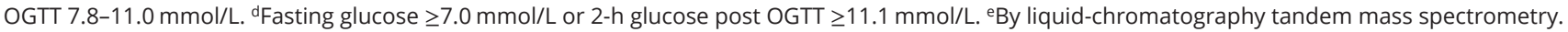
fBy bioimpedance.

MET, metabolic equivalent of task.

\section{Safety and adverse events}

Five participants discontinued the study because of side effects, two in the treatment group (gastrointestinal complaints and dizziness) and three in the placebo group (gastrointestinal complaints, anxiety and hypoglycaemia). Moreover, participants who completed the study reported gastrointestinal issues (treatment, $n=6$, placebo, $n=5$ ), dizziness (placebo, $n=1$ ), polyuria (treatment, $n=1$ ) and musculoskeletal symptoms (placebo, $n=1$ ). None of the 


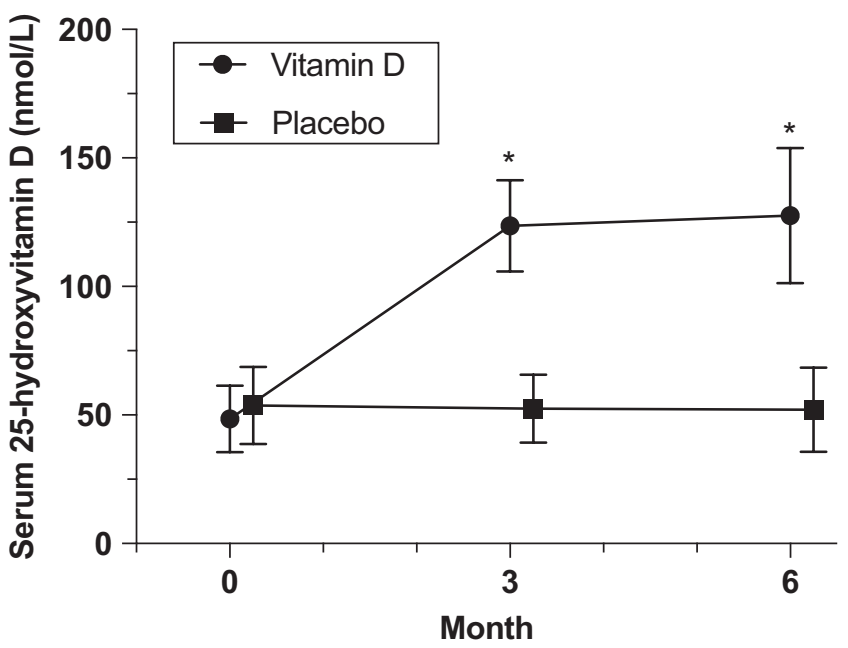

\section{Figure 2}

Mean (SD) serum 25-hydroxyvitamin D concentrations at baseline and after 3 and 6 months in the vitamin $D$ and placebo groups. ${ }^{*} P<0.001$ for the difference between groups.

participants developed hypercalcaemia, hypercalciuria or nephrolithiasis during the trial.

\section{Discussion}

In this randomised, placebo-controlled trial conducted in individuals at high risk of type 2 diabetes or with newly diagnosed type 2 diabetes, vitamin $\mathrm{D}_{3}$ supplementation at a dosage of $5000 \mathrm{IU}$ once daily for 6 months significantly increased peripheral insulin sensitivity, as measured by the gold-standard hyperinsulinemic-euglycemic clamp. A subgroup analysis revealed that this effect appeared to be more important in subjects with new diabetes or newly diagnosed diabetes at baseline. Moreover, although there were no between-group differences in indices of insulin secretion, there was a significant beneficial effect of vitamin $\mathrm{D}$ on the disposition index, suggesting that vitamin $\mathrm{D}$ may improve $\beta$-cell function. However, there was no effect of vitamin D supplementation on any measures of insulin sensitivity derived from fasting values and from the OGTT, anthropometric measures, blood pressure, fasting and 2-h glucose and $\mathrm{HbA}_{1 \mathrm{c}}$.

All five RCTs that used the hyperinsulinemiceuglycemic clamp failed to demonstrate a beneficial effect of vitamin D on insulin sensitivity. However, three of them were limited by small sample size and short duration of treatment. Indeed, one study treated 18 healthy subjects with $1.5 \mu \mathrm{g}$ of calcitriol daily for 7 days, while in another study, 12 healthy subjects received 50,000 IU of vitamin $\mathrm{D}_{2}$ weekly for 8 weeks $(6,7)$. The third trial included 16 patients with type 2 diabetes who were supplemented with vitamin $D_{3} 11,200$ IU daily for 2 weeks and then $5600 \mathrm{IU}$ daily for 10 weeks (8). While insulin sensitivity did not differ between groups, borderline improvements in insulin secretion were noted in the treatment group. In the fourth trial, the effect of a bolus dose of $100,000 \mathrm{IU}$ of vitamin $\mathrm{D}_{3}$ followed by 4,000IU daily for 16 weeks in 65 overweight and vitamin D-deficient participants was evaluated (10). Compared with our trial, participants in this study were healthier and had a better insulin sensitivity profile, with a higher baseline $\mathrm{M}$-value $(6.7 \pm 2.9$ vs $4.1 \pm 2.3 \mathrm{mg} / \mathrm{kg} \times \mathrm{min})$. Results of this study are concordant with our subgroup analysis showing that vitamin D supplementation did not change $\mathrm{M}$-value in participants with normal glucose tolerance. Finally, in a 6-month trial, 62 participants of Nordic or South Asian ethnicity with type 2 diabetes and vitamin $\mathrm{D}$ deficiency were treated with a single high dose of vitamin D3 400,000IU, with an additional dose of $200,000 \mathrm{IU}$ at 4 weeks if serum $25(\mathrm{OH}) \mathrm{D}$ was below $100 \mathrm{nmol} / \mathrm{L}$ (9). Divergence in results with our study may

Table 2 Mean baseline and 6-month values and the mean absolute changes in M-value and M/l ratio in the treatment and placebo groups.

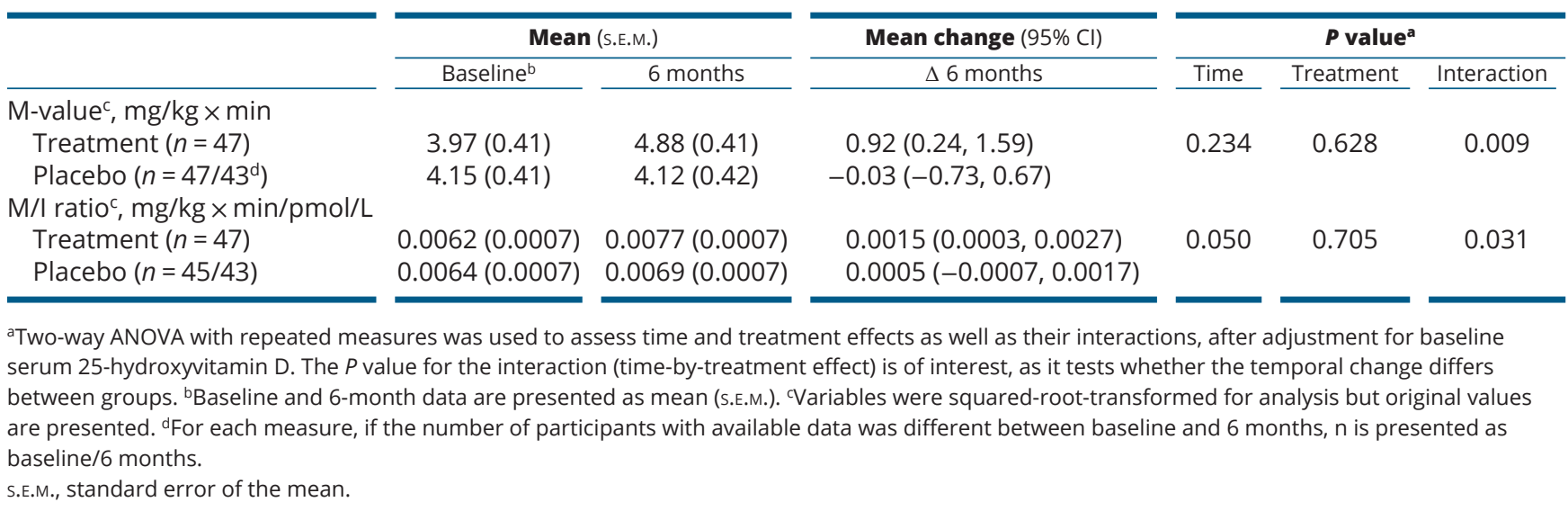

https://eje.bioscientifica.com 
Table 3 Mean baseline and 6-month values and the mean absolute changes in M-value in the subgroups of participants with normal glucose tolerance, prediabetes or diabetes at baseline.

\begin{tabular}{|c|c|c|c|c|c|c|}
\hline & \multicolumn{2}{|c|}{ Mean (S.E.M.) } & \multirow{2}{*}{$\begin{array}{c}\text { Mean change }(95 \% \mathrm{Cl}) \\
\Delta 6 \text { months }\end{array}$} & \multicolumn{3}{|c|}{ P value ${ }^{a}$} \\
\hline & Baseline $^{c}$ & 6 months & & Time & Treatment & Interaction \\
\hline \multicolumn{7}{|l|}{ M-value ${ }^{b}, \mathrm{mg} / \mathrm{kg} \times \min$} \\
\hline \multicolumn{7}{|c|}{ Normal glucose tolerance } \\
\hline Treatment $(n=22)$ & $5.49(0.67)$ & $5.94(0.67)$ & $0.45(-0.74,1.64)$ & 0.641 & 0.788 & 0.677 \\
\hline Placebo $\left(n=19 / 17^{\mathrm{d}}\right)$ & $5.31(0.72)$ & $5.75(0.75)$ & $0.43(-0.91,1.77)$ & & & \\
\hline \multicolumn{7}{|l|}{ Prediabetes } \\
\hline Treatment $(n=16)$ & $3.13(0.56)$ & $4.38(0.56)$ & $1.25(0.12,2.38)$ & 0.591 & 0.952 & 0.015 \\
\hline Placebo $(n=18 / 16)$ & $3.88(0.52)$ & $3.32(0.55)$ & $-0.56(-1.68,0.56)$ & & & \\
\hline \multicolumn{7}{|l|}{ Diabetes } \\
\hline Treatment $(n=9)$ & $1.50(0.49)$ & $2.96(0.49)$ & $1.46(0.58,2.34)$ & 0.080 & 0.562 & 0.030 \\
\hline Placebo $(n=10)$ & $2.62(0.46)$ & $2.70(0.46)$ & $0.08(-0.76,0.91)$ & & & \\
\hline
\end{tabular}

aTwo-way ANOVA with repeated measures was used to assess time and treatment effects as well as their interactions, after adjustment for baseline serum 25-hydroxyvitamin D. The $P$ value for the interaction (time-by-treatment effect) is of interest, as it tests whether the temporal change differs between groups. bVariables were squared-root-transformed for analysis but original values are presented. 'Baseline and 6-month data are presented as mean (S.E.M.). ${ }^{\mathrm{d} F o r}$ each measure, if the number of participants with available data was different between baseline and 6 months, $n$ is presented as baseline/ 6 months. S.E.M., standard error of the mean.

be explained by the lack of sustained concentrations of serum $25(\mathrm{OH}) \mathrm{D}$ in the treatment group, with a mean of $53.7 \pm 9.2 \mathrm{nmol} / \mathrm{L}$ at 6 months and by the inclusion of participants with long standing type 2 diabetes (mean diabetes duration of $11.0 \pm 6.6$ years and $7.9 \pm 5.7$ years in the vitamin D and placebo group, respectively), compared to our trial, which included participants at high risk for diabetes or with newly diagnosed type 2 diabetes. However, it remains unclear how the diabetes duration could have affected the results. Furthermore, no effect of vitamin $\mathrm{D}$ was found in two RCTs that used the hyperglycemic clamp to evaluate insulin sensitivity. One was performed in 104 healthy subjects who received 20,000 IU of vitamin $\mathrm{D}_{3}$ twice weekly for 6 months and the other one in 44 participants with prediabetes or type 2 diabetes who were treated with $30,000 \mathrm{IU}$ of vitamin $\mathrm{D}_{3}$ once weekly for 8 weeks $(18,19)$. Nevertheless, the hyperglycemic clamp is less accurate than the gold-standard hyperinsulinemiceuglycemic clamp to estimate insulin sensitivity (20).

In concordance with three recent meta-analyses, one including 23 RCTs in patients with type 2 diabetes, another including 35 RCTs performed in various populations and the third one including 10 RCTs in prediabetes patients $(4,5$, 21 ), we did not find any effect of vitamin D supplementation on measures of insulin sensitivity and insulin secretion based on fasting indices and the OGTT. The vast majority of RCTs, and therefore those included in the meta-analyses, used indirect insulin sensitivity markers such as HOMA and Matsuda instead of the hyperinsulinemic-euglycemic clamp. Just like the population included in our study, many previous trials were performed in insulin-resistant participants, and most of them have shown negative results with the use of surrogate markers of insulin sensitivity
$(13,22,23,24,25,26,27)$. One trial demonstrated a significant improvement in insulin sensitivity assessed by HOMA2\%S in 81 vitamin D-deficient South Asian women with insulin resistance treated with vitamin $\mathrm{D}_{3} 4,000 \mathrm{IU}$ daily for 6 months, and a second one showed a significant decrease in HOMA-IR in Iranian women with polycystic ovary syndrome $(16,28)$. However, these results may not be generalisable to Caucasian populations.

The discordant effects of vitamin D supplementation that we observed on insulin sensitivity measures, with a significant beneficial effect on M-value and no difference on HOMA2\%S and Matsuda indices, suggests that vitamin $\mathrm{D}$ acts mainly on peripheral insulin sensitivity. Indeed, HOMA2\%S primarily reflects hepatic insulin sensitivity, and Matsuda whole-body insulin sensitivity with a major contribution of hepatic insulin sensitivity (29), whereas the hyperinsulinemic-euglycemic clamp (M-value), at the insulin dose that we used, evaluates predominantly muscle insulin sensitivity $(30,31)$. Although the exact mechanisms by which vitamin D influences muscle insulin sensitivity in humans remain to be elucidated, preclinical evidence suggests that vitamin D may improve diabetes-induced muscle dysfunction and atrophy (32) as well as muscle fat infiltration (33). Also, vitamin D could increase glucose uptake in adipose tissue and muscle by stimulating GLUT-4 expression $(34,35)$ and reduce lowgrade chronic systemic inflammation $(36,37)$.

Another notable finding of our study is the significant beneficial effect of vitamin $\mathrm{D}$ supplementation on disposition index, a measure of $\beta$-cell compensatory capacity, with stability in the control group and improvement in the treatment group. Preservation of $\beta$-cell function is important, as it was shown to predict reduced 
Table 4 Mean baseline and 6-month values and the mean absolute changes in insulin sensitivity, insulin secretion, $\beta$-cell function and metabolic markers in the treatment and placebo groups.

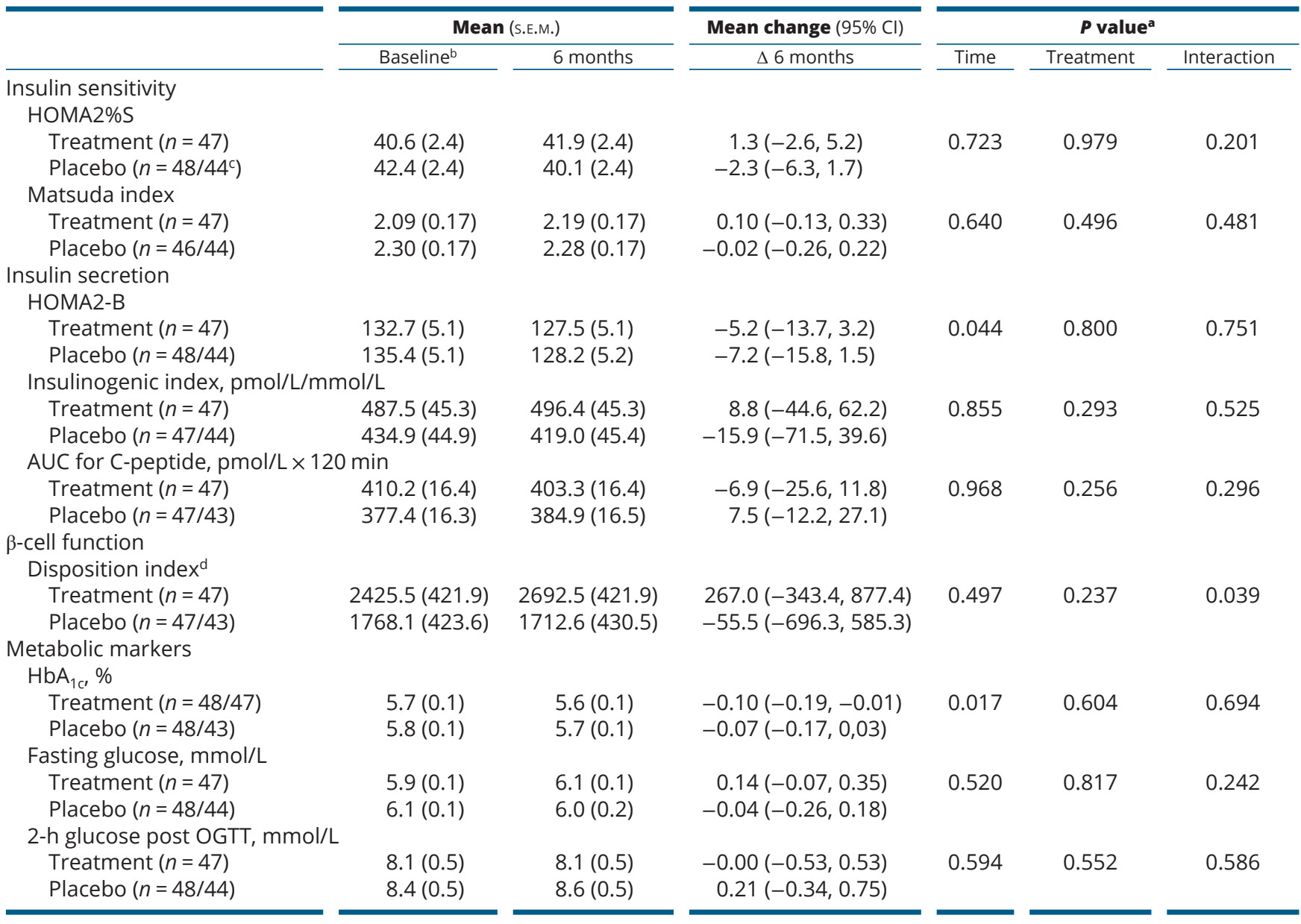

aTwo-way ANOVA with repeated measures was used to assess time and treatment effects as well as their interactions, after adjustment for baseline serum 25-hydroxyvitamin $\mathrm{D}$. The $P$ value for the interaction (time-by-treatment effect) is the one of interest as it tests whether the temporal change

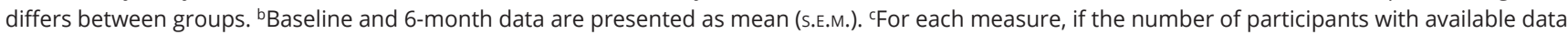
was different between baseline and 6 months, $n$ is presented as baseline/ 6 months. 'Calculated by multiplying M-value by insulinogenic index. Variable was squared-root-transformed for analysis but original values are presented. Mean change for the squared-root values are $4.03(0.05,8.01)$ in the treatment group and $-2.05(-6.23,2.14)$ in the control group.

AUC, area under the curve; HOMA2\%S, Homeostasis Model Assessment 2 index of insulin sensitivity; HOMA2-B, Homeostasis Model Assessment 2 index of $\beta$-cell function; OGTT, oral glucose tolerance test; S.E.M., standard error of the mean.

diabetes risk (38). Indeed, DeFronzo et al. demonstrated that deterioration of $\beta$-cell function, assessed by the disposition index, is the strongest predictor of conversion to diabetes in subjects with impaired glucose tolerance (39). Even though we observed no differences in indices of insulin secretion following OGTT between groups, a beneficial effect of vitamin $\mathrm{D}$ on insulin secretion relative to insulin sensitivity was seen, reflected by the disposition index. Moreover, we could have missed positive effects of vitamin D on insulin secretion per se, as we did not use the hyperglycemic clamp, the gold-standard method to assess insulin secretion (20). Mechanisms by which vitamin $D$ plays a role on preservation of $\beta$-cell function remain largely unknown. However, previous studies have shown that pancreatic $\beta$-cells contain high levels of vitamin $\mathrm{D}$ receptor and that vitamin $\mathrm{D}$ enhances $\beta$-cell intracellular calcium concentration and influx $(40,41)$.

Our study has notable strengths including the randomised, double-blind design and the use of the goldstandard hyperinsulinemic-euglycemic clamp to evaluate insulin sensitivity. Furthermore, we selected participants at high risk for type 2 diabetes or with newly diagnosed type 2 diabetes, a group that had not been specifically studied using the clamp. Another strength is the use of high-dose vitamin D supplementation for 6 months and the high rate of compliance, with a large difference in serum 25(OH)D during the study between the treatment and control groups. However, limitations include 
Table 5 Mean baseline and 6-month values and the mean absolute changes in anthropometry and blood pressure in the treatment and placebo groups.

\begin{tabular}{|c|c|c|c|c|c|c|}
\hline & \multirow{2}{*}{$\begin{array}{c}\text { Mean (S.E.M.) } \\
\text { Baseline }^{\text {b }}\end{array}$} & \multicolumn{2}{|c|}{ Mean change from baseline $(95 \% \mathrm{Cl})$} & \multicolumn{3}{|c|}{ P value ${ }^{a}$} \\
\hline & & $\Delta 3$ months & $\Delta 6$ months & Time & Treatment & Interaction \\
\hline \multicolumn{7}{|l|}{ Weight, kg } \\
\hline Treatment $\left(n=48 / 47^{c}\right)$ & $91.0(2.1)$ & $0.01(-0.63,0.65)$ & $-0.59(-1.49,0.31)$ & 0.004 & 0.911 & 0.696 \\
\hline Placebo $(n=48 / 44)$ & $90.7(2.1)$ & $0.14(-0.51,0.80)$ & $-0.84(-1.76,0.09)$ & & & \\
\hline \multicolumn{7}{|l|}{$\mathrm{BMI}, \mathrm{kg} / \mathrm{m}^{2}$} \\
\hline Treatment $(n=48 / 47)$ & $32.2(0.6)$ & $0.02(-0.20,0.24)$ & $-0.18(-0.49,0.13)$ & 0.004 & 0.868 & 0.674 \\
\hline Placebo $(n=48 / 44)$ & $32.1(0.6)$ & $0.06(-0.17,0.28)$ & $-0.28(-0.60,0.03)$ & & & \\
\hline \multicolumn{7}{|c|}{ Fat mass by bioimpedance, $\%$} \\
\hline Treatment $(n=36)$ & $38.4(1.3)$ & ND & $-0.32(-1.00,0.37)$ & 0.026 & 0.303 & 0.305 \\
\hline Placebo $(n=30)$ & $36.8(1.3)$ & ND & $-0.84(-1.59,-0.09)$ & & & \\
\hline \multicolumn{7}{|l|}{ Waist circumference, cm } \\
\hline Treatment $(n=48 / 47)$ & $107.9(1.4)$ & $0.75(-0.02,1.53)$ & $0.18(-0.90,1.26)$ & 0.020 & 0.826 & 0.814 \\
\hline Placebo $(n=48 / 44)$ & $108.6(1.4)$ & $0.39(-0.40,1.19)$ & $-0.19(-1.30,0.92)$ & & & \\
\hline \multicolumn{7}{|l|}{ Hip circumference, $\mathrm{cm}$} \\
\hline Treatment $(n=46)$ & $112.5(1.2)$ & ND & $0.41(-0.52,1.35)$ & 0.912 & 0.205 & 0.179 \\
\hline Placebo $(n=47 / 44)$ & $112.9(1.2)$ & ND & $-0.49(-1.43,0.45)$ & & & \\
\hline \multicolumn{7}{|l|}{$\mathrm{SBP}, \mathrm{mmHg}$} \\
\hline Treatment $(n=48 / 47)$ & $129.4(2.2)$ & $1.52(-1.83,4.88)$ & $-1.61(-5.94,2,72)$ & 0.001 & 0.756 & 0.526 \\
\hline Placebo $(n=47 / 44)$ & $131.0(2.2)$ & $1.85(-1.57,5.27)$ & $-4.06(-8.49,0.37)$ & & & \\
\hline \multicolumn{7}{|l|}{$\mathrm{DBP}, \mathrm{mmHg}$} \\
\hline Treatment $(n=48 / 47)$ & $76.5(1.4)$ & $0.66(-1.33,2.65)$ & $-2.45(-5.04,0.15)$ & $<0.001$ & 0.576 & 0.487 \\
\hline Placebo $(n=48 / 44)$ & $76.3(1.4)$ & $2.22(0.20,4.25)$ & $-0.37(-3.03,2.28)$ & & & \\
\hline
\end{tabular}

aTwo-way ANOVA with repeated measures was used to assess time and treatment effects as well as their interaction, after adjustment for baseline serum 25-hydroxyvitamin D. The $P$ value for the interaction (time-by-treatment effect) is the one of interest as it tests whether the temporal change differs between groups. ${ }^{b}$ Baseline data are presented as mean (S.E.M.). 'For each measure, if the number of participants with available data was different between baseline and 6 months, $n$ is presented as baseline/ 6 months.

DBP, diastolic blood pressure; ND, not documented; SBP, systolic blood pressure; s.E.M., standard error of the mean.

the selection of a Caucasian population, restricting generalizability to other ethnic groups. Moreover, we did not reach our target sample size. However, our sample of 96 participants still had the power to detect a medium to large effect. Indeed, using the same criteria as mentioned in the methods section, it was still possible to detect an effect size of $d=0.58$ with a sample size of 96 participants (where $\mathrm{d}$ of 0.5 is considered a medium effect and 0.80 a large effect), compared to our planned sample of 120 participants that could detect a medium effect $(\mathrm{d}=0.52)$ (17). Since effect sizes in the present study were mostly small, it is probable that reaching the target sample size would not have changed the conclusions. Furthermore, the sample size calculation was based on postmenopausal women, even though the present study included men and women, due to lack of available data at the time of the study. Another limitation is that the mean baseline serum $25(\mathrm{OH}) \mathrm{D}$ was higher than expected and only about half of the participants had vitamin D deficiency at study entry due to different methods for serum 25(OH)D measurement and to time difference of up to 3 months between screening and baseline visits. Although subgroup analysis restricted to participants with baseline $25(\mathrm{OH}) \mathrm{D}<50 \mathrm{nmol} / \mathrm{L}$ did not show any significant differences between groups, these results should be interpreted with caution due to reduced study power and the post hoc nature of the analysis. Additionally, although both groups were comparable in terms of confounding factors such as sun exposure, dietary intake of calcium and vitamin D and physical activity, the assessment methods employed, such as the use of a nonvalidated questionnaire for sun exposure, may have failed to capture differences. Furthermore, although a minority of patients dropped out of the study, excluded participants had a better insulin sensitivity profile. These selection and attrition bias could have overestimated the effect in the mixed models. Finally, as we did not use tracer infusion to estimate glucose rate of appearance and disappearance and as we used an insulin dose that may not have suppressed completely endogenous glucose production in the most highly insulin-resistant participants, we may have underestimated peripheral insulin sensitivity as assessed by M-value or M/I.

In conclusion, this study showed that high-dose vitamin D supplementation for 6 months significantly improved peripheral insulin sensitivity, as assessed by the hyperinsulinemic-euglycemic clamp, and $\beta$-cell function in individuals at high risk of diabetes or with newly diagnosed type 2 diabetes. Of interest, two large 
RCTs evaluating the effect of high-dose vitamin $D_{3}$ (20 000 IU/week for 5 years and $4000 \mathrm{IU} /$ day for a median of 2.5 years) in patients with prediabetes who were mostly vitamin $\mathrm{D}$ sufficient at baseline did not show any effect on progression to type 2 diabetes $(42,43)$. Larger and longerterm RCTs are required to evaluate whether subgroups of patients including those with low vitamin D status may benefit from vitamin D supplementation.

\section{Declaration of interest}

A T receives research funding from Johnson \& Johnson Medical Companies, Pfizer and Medtronic for studies unrelated to this project. C G, S J W, M C V and $A M$ received research funding from the Food \& Health Programmatic grant program from the Canadian Institutes of Health Research (CIHR). A M holds a Canadian Institutes of Health Research (ClHR)/Pfizer research Chair in the pathogenesis of insulin resistance and cardiovascular diseases. M C V is tier 1 Canada Research Chair in Genomics Applied to Nutrition and Metabolic Health. C G received research funding from Technologies Khlôros. She is also a Scholar of the Fonds de Recherche du Québec-Santé and a recipient of a New Investigator award from Diabetes Canada. The other authors have nothing to disclose.

\section{Funding}

This work was supported by Diabetes Canada (Grant \# OG-3-12-3681) and by the CHU de Québec-Université Laval Research Center.

\section{Author contribution statement}

C G formulated the research question, C G and S J W designed research; C G conducted research; A S J analysed data; P L wrote the first draft of the paper; C G had primary responsibility for final content; and all authors critically revised the protocol, read and approved the final version of the manuscript prior to submission.

\section{Acknowledgements}

The authors would like to thank all the participants for their commitment as well as the research assistant Sarah Chouinard-Castonguay, all the nurses and research trainees (Claudia Savard, Antoine Leduc, Mehdi Bihya, Véronique Thibeault) for their support in running the trial. The authors also express gratitude to Dr Caroline Albert for vitamin D analysis.

\section{References}

1 Kayaniyil S, Vieth R, Retnakaran R, Knight JA, Qi Y, Gerstein HC, Perkins BA, Harris SB, Zinman B \& Hanley AJ. Association of vitamin $\mathrm{D}$ with insulin resistance and beta-cell dysfunction in subjects at risk for type 2 diabetes. Diabetes Care 201033 1379-1381. (https://doi. org/10.2337/dc09-2321)

2 Gagnon C, Lu ZX, Magliano DJ, Dunstan DW, Shaw JE, Zimmet PZ, Sikaris K, Grantham N, Ebeling PR \& Daly RM. Serum 25-hydroxyvitamin $\mathrm{D}$, calcium intake, and risk of type 2 diabetes after 5 years: results from a national, population-based prospective study (the Australian Diabetes, Obesity and Lifestyle study). Diabetes Care 201134 1133-1138. (https://doi.org/10.2337/dc10-2167)

3 Holick MF. Vitamin D deficiency. New England Journal of Medicine 2007357 266-281. (https://doi.org/10.1056/NEJMra070553)

4 Krul-Poel YH, Ter Wee MM, Lips P \& Simsek S. MANAGEMENT of ENDOCRINE DISEASE: The effect of vitamin D supplementation on glycaemic control in patients with type 2 diabetes mellitus: a systematic review and meta-analysis. European Journal of Endocrinology 2017176 R1-R14. (https://doi.org/10.1530/EJE-16-0391)

5 Seida JC, Mitri J, Colmers IN, Majumdar SR, Davidson MB, Edwards AL, Hanley DA, Pittas AG, Tjosvold L \& Johnson JA. Clinical review: effect of vitamin D3 supplementation on improving glucose homeostasis and preventing diabetes: a systematic review and metaanalysis. Journal of Clinical Endocrinology and Metabolism 201499 3551-3560. (https://doi.org/10.1210/jc.2014-2136)

6 Fliser D, Stefanski A, Franek E, Fode P, Gudarzi A \& Ritz E. No effect of calcitriol on insulin-mediated glucose uptake in healthy subjects. European Journal of Clinical Investigation 199727 629-633. (https:// doi.org/10.1046/j.1365-2362.1997.1520699.x)

7 Simha V, Mahmood M, Ansari M, Spellman CW \& Shah P. Effect of vitamin D replacement on insulin sensitivity in subjects with vitamin D deficiency. Journal of Investigative Medicine $2012 \mathbf{6 0}$ 1214-1218. (https://doi.org/10.2310/JIM.0b013e3182747c06)

8 Kampmann U, Mosekilde L, Juhl C, Moller N, Christensen B, Rejnmark L, Wamberg L \& Orskov L. Effects of 12 weeks high dose vitamin D3 treatment on insulin sensitivity, beta cell function, and metabolic markers in patients with type 2 diabetes and vitamin D insufficiency - a double-blind, randomized, placebo-controlled trial. Metabolism: Clinical and Experimental 201463 1115-1124. (https:// doi.org/10.1016/j.metabol.2014.06.008)

9 Gulseth HL, Wium C, Angel K, Eriksen EF \& Birkeland KI. Effects of vitamin D supplementation on insulin sensitivity and insulin secretion in subjects with type 2 diabetes and vitamin D deficiency: a randomized controlled trial. Diabetes Care 201740 872-878. (https:// doi.org/10.2337/dc16-2302)

10 Mousa A, Naderpoor N, de Courten MP, Teede H, Kellow N, Walker K, Scragg R \& de Courten B. Vitamin D supplementation has no effect on insulin sensitivity or secretion in vitamin D-deficient, overweight or obese adults: a randomized placebo-controlled trial. American Journal of Clinical Nutrition $2017 \mathbf{1 0 5}$ 1372-1381. (https://doi. org/10.3945/ajcn.117.152736)

11 Pocock SJ \& Simon R. Sequential treatment assignment with balancing for prognostic factors in the controlled clinical trial. Biometrics 197531 103-115. (https://doi.org/10.2307/2529712)

12 Moher D, Hopewell S, Schulz KF, Montori V, Gotzsche PC, Devereaux PJ, Elbourne D, Egger M \& Altman DG. CONSORT 2010 explanation and elaboration: updated guidelines for reporting parallel group randomised trials. BMJ 2010340 c869. (https://doi.org/10.1136/ bmj.c869)

13 Gagnon C, Daly RM, Carpentier A, Lu ZX, Shore-Lorenti C, Sikaris K, Jean S \& Ebeling PR. Effects of combined calcium and vitamin D supplementation on insulin secretion, insulin sensitivity and beta-cell function in multi-ethnic vitamin D-deficient adults at risk for type 2 diabetes: a pilot randomized, placebo-controlled trial. PLOS ONE 20149 e109607. (https://doi.org/10.1371/journal. pone.0109607)

14 Wacker M \& Holick MF. Sunlight and vitamin D: a global perspective for health. Dermato-Endocrinology 20135 51-108. (https://doi. org/10.4161/derm.24494)

15 Labonte MÈ, Cyr A, Baril-Gravel L, Royer MM \& Lamarche B. Validity and reproducibility of a web-based, self-administered food frequency questionnaire. European Journal of Clinical Nutrition 201266 166-173. (https://doi.org/10.1038/ejcn.2011.163)

16 von Hurst PR, Stonehouse W \& Coad J. Vitamin D supplementation reduces insulin resistance in South Asian women living in New Zealand who are insulin resistant and vitamin $\mathrm{D}$ deficient - a randomised, placebo-controlled trial. British Journal of Nutrition 2010 103 549-555. (https://doi.org/10.1017/S0007114509992017)

17 Sawilowsky SS. New effect size rules of thumb. Journal of Modern Applied Statistical Methods 20098 597-599. (https://doi.org/10.22237/ jmasm/1257035100)

18 Grimnes G, Figenschau Y, Almas B \& Jorde R. Vitamin D, insulin secretion, sensitivity, and lipids: results from a case-control study and 
a randomized controlled trial using hyperglycemic clamp technique. Diabetes 201160 2748-2757. (https://doi.org/10.2337/db11-0650)

19 Wagner H, Alvarsson M, Mannheimer B, Degerblad M \&

Ostenson CG. No effect of high-dose vitamin D treatment on betacell function, insulin sensitivity, or glucose homeostasis in subjects with abnormal glucose tolerance: a randomized clinical trial. Diabetes Care 201639 345-352. (https://doi.org/10.2337/dc15-1057)

20 DeFronzo RA, Tobin JD \& Andres R. Glucose clamp technique: a method for quantifying insulin secretion and resistance. American Journal of Physiology 1979237 E214-E223. (https://doi.org/10.1152/ ajpendo.1979.237.3.E214)

21 Poolsup N, Suksomboon N \& Plordplong N. Effect of vitamin D supplementation on insulin resistance and glycaemic control in prediabetes: a systematic review and meta-analysis. Diabetic Medicine 201633 290-299. (https://doi.org/10.1111/dme.12893)

22 Davidson MB, Duran P, Lee ML \& Friedman TC. High-dose vitamin D supplementation in people with prediabetes and hypovitaminosis D. Diabetes Care 201336 260-266. (https://doi.org/10.2337/dc12-1204)

23 Moreira-Lucas TS, Duncan AM, Rabasa-Lhoret R, Vieth R, Gibbs AL, Badawi A \& Wolever TM. Effect of vitamin D supplementation on oral glucose tolerance in individuals with low vitamin D status and increased risk for developing type 2 diabetes (EVIDENCE): a doubleblind, randomized, placebo-controlled clinical trial. Diabetes, Obesity and Metabolism 201719 133-141. (https://doi.org/10.1111/dom.12794)

24 Oosterwerff MM, Eekhoff EM, Van Schoor NM, Boeke AJ, Nanayakkara P, Meijnen R, Knol DL, Kramer MH \& Lips P. Effect of moderate-dose vitamin D supplementation on insulin sensitivity in vitamin D-deficient non-Western immigrants in the Netherlands: a randomized placebo-controlled trial. American Journal of Clinical Nutrition 2014100 152-160. (https://doi.org/10.3945/ ajcn.113.069260)

25 Sollid ST, Hutchinson MYS, Fuskevag OM, Figenschau Y, Joakimsen RM, Schirmer H, Njolstad I, Svartberg J, Kamycheva E $\&$ Jorde R. No effect of high-dose vitamin D supplementation on glycemic status or cardiovascular risk factors in subjects with prediabetes. Diabetes Care 201437 2123-2131. (https://doi. org/10.2337/dc14-0218)

26 Hoseini SA, Aminorroaya A, Iraj B \& Amini M. The effects of oral vitamin $\mathrm{D}$ on insulin resistance in pre-diabetic patients. Journal of Research in Medical Sciences 201318 47-51.

27 Tuomainen TP, Virtanen JK, Voutilainen S, Nurmi T, Mursu J, de Mello VD, Schwab U, Hakumaki M, Pulkki K \& Uusitupa M. Glucose metabolism effects of vitamin D in prediabetes: the VitDmet randomized placebo-controlled supplementation study. Journal of Diabetes Research 20152015 672653. (https://doi. org/10.1155/2015/672653)

28 Foroozanfard F, Talebi M, Samimi M, Mehrabi S, Badehnoosh B, Jamilian M, Maktabi M \& Asemi Z. Effect of two different doses of vitamin D supplementation on metabolic profiles of insulin-resistant patients with polycystic ovary syndrome: a randomized, doubleblind, placebo-controlled trial. Hormone and Metabolic Research 2017 49 612-617. (https://doi.org/10.1055/s-0043-112346)

29 Matsuda M \& DeFronzo RA. Insulin sensitivity indices obtained from oral glucose tolerance testing: comparison with the euglycemic insulin clamp. Diabetes Care 199922 1462-1470. (https://doi. org/10.2337/diacare.22.9.1462)

30 Rabasa-Lhoret R \& Laville M. How to measure insulin sensitivity in clinical practice? Diabetes and Metabolism 200127 201-208.

31 DeFronzo RA \& Tripathy D. Skeletal muscle insulin resistance is the primary defect in type 2 diabetes. Diabetes Care 200932 (Supplement 2) S157-S163. (https://doi.org/10.2337/dc09-S302)
32 Amin SN, Hussein UK, Yassa HD, Hassan SS \& Rashed LA. Synergistic actions of vitamin D and metformin on skeletal muscles and insulin resistance of type 2 diabetic rats. Journal of Cellular Physiology 2018 233 5768-5779. (https://doi.org/10.1002/jcp.26300)

33 Gilsanz V, Kremer A, Mo AO, Wren TA \& Kremer R. Vitamin D status and its relation to muscle mass and muscle fat in young women. Journal of Clinical Endocrinology and Metabolism 201095 1595-1601. (https://doi.org/10.1210/jc.2009-2309)

34 Manna P, Achari AE \& Jain SK. Vitamin D supplementation inhibits oxidative stress and upregulate SIRT1/AMPK/GLUT4 cascade in high glucose-treated 3T3L1 adipocytes and in adipose tissue of high fat diet-fed diabetic mice. Archives of Biochemistry and Biophysics 2017615 22-34. (https://doi.org/10.1016/j. abb.2017.01.002)

35 Castro AJ, Frederico MJ, Cazarolli LH, Bretanha LC, Tavares Lde C, Buss Zda S, Dutra MF, de Souza AZ, Pizzolatti MG \& Silva FR. Betulinic acid and 1,25(OH)(2) vitamin $\mathrm{D}(3)$ share intracellular signal transduction in glucose homeostasis in soleus muscle. International Journal of Biochemistry and Cell Biology 201448 18-27. (https://doi. org/10.1016/j.biocel.2013.11.020)

36 Shab-Bidar S, Neyestani TR, Djazayery A, Eshraghian MR, Houshiarrad A, Kalayi A, Shariatzadeh N, Khalaji N \& Gharavi A. Improvement of vitamin D status resulted in amelioration of biomarkers of systemic inflammation in the subjects with type 2 diabetes. Diabetes/Metabolism Research and Reviews 201228 424-430. (https://doi.org/10.1002/dmrr.2290)

37 Roy P, Nadeau M, Valle M, Bellmann K, Marette A, Tchernof A \& Gagnon C. Vitamin D reduces LPS-induced cytokine release in omental adipose tissue of women but not men. Steroids $2015 \mathbf{1 0 4}$ 65-71. (https://doi.org/10.1016/i.steroids.2015.08.014)

38 Utzschneider KM, Prigeon RL, Faulenbach MV, Tong J, Carr DB, Boyko EJ, Leonetti DL, McNeely MJ, Fujimoto WY \& Kahn SE. Oral disposition index predicts the development of future diabetes above and beyond fasting and 2-h glucose levels. Diabetes Care 200932 335-341. (https://doi.org/10.2337/dc08-1478)

39 Defronzo RA, Tripathy D, Schwenke DC, Banerji M, Bray GA, Buchanan TA, Clement SC, Henry RR, Kitabchi AE, Mudaliar Set al. Prediction of diabetes based on baseline metabolic characteristics in individuals at high risk. Diabetes Care 201336 3607-3612. (https:// doi.org/10.2337/dc13-0520)

40 Neelankal John A \& Jiang FX. An overview of type 2 diabetes and importance of vitamin D3-vitamin D receptor interaction in pancreatic beta-cells. Journal of Diabetes and its Complications 201832 429-443. (https://doi.org/10.1016/j. jdiacomp.2017.12.002)

41 Kajikawa M, Ishida H, Fujimoto S, Mukai E, Nishimura M, Fujita J Tsuura Y, Okamoto Y, Norman AW \& Seino Y. An insulinotropic effect of vitamin D analog with increasing intracellular Ca2+ concentration in pancreatic beta-cells through nongenomic signal transduction. Endocrinology 1999140 4706-4712. (https://doi. org/10.1210/endo.140.10.7025)

42 Jorde R, Sollid ST, Svartberg J, Schirmer H, Joakimsen RM, Njolstad I, Fuskevag OM, Figenschau Y \& Hutchinson MY. Vitamin D 20,000 IU per week for five years does not prevent progression from prediabetes to diabetes. Journal of Clinical Endocrinology and Metabolism 2016101 1647-1655. (https://doi.org/10.1210/jc.2015-4013)

43 Pittas AG, Dawson-Hughes B, Sheehan P, Ware JH, Knowler WC, Aroda VR, Brodsky I, Ceglia L, Chadha C, Chatterjee Ret al. Vitamin D supplementation and prevention of Type 2 diabetes. New England Journal of Medicine 2019 [epub]. (https://doi.org/10.1056/ NEJMoa1900906) 